\title{
Delaware Sosyal-Duygusal Yeterlik Ölçeğinin (DSDY-Ö) Türk Diline Uyarlanması*
}

\section{Adaptation of the Delaware Social-Emotional Competency (DSECS-S) Scale into Turkish Language}

Bijen FíLiz**

\author{
Mehmet DURNALI $^{* * *}$ (iD
}

Received: 07 September 2018

Research Article

Accepted: 19 March 2019

\begin{abstract}
The aim of this study is to adapt The Delaware Social-Emotional Competency Scale into Turkish language so that social-emotional competency of students can be examined through testing the language validity and conducting Exploratory Factor Analysis (EFA) and Confirmatory Factor Analysis (CFA). While the sample for EFA consisted of 338, the sample for CFA consisted of 220 different high school students. Since the CFA was administered first and it was decided to administer the EFA. The first and 12nd items were taken out of the scale considering the total item correlation before EFA. Two sub-dimensional structures were obtained as a result of the AFA administered with the remaining items. Sub-dimensions were given the names "self awareness" and "social awareness" in accordance with the literature. In order to test the structure obtained from the EFA, CFA was administered with different data sets and the factor structure was determined to be acceptable. The internal consistency coefficient for the reliability study was calculated as .70 The Pearson Moments Multiplication Correlation Coefficient calculated for the test-retest reliability study was found to be significant. The scale is a valid and reliable tool that can be used in Turkish culture.
\end{abstract}

Keywords: social-emotional competence, validity, reliability, adaptation.

ÖZ: Bu çalışmada öğrencilerin sosyal-duygusal yeterliklerini değerlendirebilmek amacıyla Mantz ve ark. tarafindan geliştirilen “Delaware Sosyal-Duygusal Yeterlik Ölçeği”nin Türk diline uyarlaması yapılmıştır. Çalışmada ölçeğin dil eşdeğerliğinin sağlanması ve faktör yapısının sınanması hedeflenmiştir. Ölçek, açımlayıcı faktör analizi (AFA) için 338 lise öğrencisi, doğrulayıcı faktör analizi (DFA) için farklı 220 lise öğrencisine uygulanmıştır. DFA analizi sonucunda bazı maddelerin .05 düzeyinde anlamli olmadiği tespit edilmiş ve AFA yapılmasına karar verilmiştir. AFA öncesi toplam madde korelasyonuna bakılarak 1 ve 12. maddeler ölçekten çıkarılmıştır. Kalan maddelerle yapılan AFA sonucunda iki alt boyutlu bir yapı elde edilmiştir. Alt boyutlara literature uygun olarak "öz farkındalık" ve "sosyal farkındalık" isimleri verilmiştir. AFA'dan elde edilen yapının test edilmesi için farklı veri grubuyla DFA yapılmış ve faktör yapısının kabul edilebilir düzeyde olduğu belirlenmiştir. Güvenirlik çalışması için iç tutarlık katsayısı .70 olarak hesaplanmıştır. Test-tekrar test güvenirlik çalışması için hesaplanan Pearson Momentler Çarpımı Korelasyon katsayısının anlamlı olduğu belirlenmiştir. Ölçek, Türk Kültüründe kullanılabilecek geçerli ve güvenilir bir araçtır.

Anahtar kelimeler: sosyal-duygusal yeterlik, geçerlik, güvenirlik, uyarlama.

\footnotetext{
* Bu çalışma, Uluslararası Eğitim ve Bilim Kongresi’nde sözlü bildiri olarak sunulmuştur (23-25 Mart 2018, Afyon). Corresponding Author: Asst. Prof. Dr., Afyon Kocatepe University, Afyonkarahisar, Turkey, bijenfiliz@aku.edu.tr, https://orcid.org/0000-0001-5863-3861

Dr., Hacettepe University, Ankara, Turkey, durnali@gmail.com, https://orcid.org/0000-0002-1318-9362
}

\section{Citation Information}

Bijen, F., \& Durnal1, M. (2019). Delaware sosyal-duygusal yeterlik ölçeğinin (DSDY-Ö) Türk diline uyarlanması. Kuramsal Eğitimbilim Dergisi [Journal of Theoretical Educational Science], 12(3), 962-977. 


\section{Giriş}

Son yıllarda birçok okul, sosyal-duygusal öğrenme (SDÖ) programlarının benimsenmesiyle öğrencilerin sosyal-mesleki yeterliklerini geliştirme çabalarını artırmıştır (Dusenbury, Weissberg, Goren, \& Domitrovich, 2014; Jones \& Bouffard, 2012). Bu bağlamda okullar, etkili SDÖ programları ile öğrencilerin sosyal-duygusal yeterliklerini geliştirmeyi amaçlamaktadır. SDÖ, başarılı bir akademik öğrenmede sosyal-duygusal faktörlerin rolünü güçlü bir şekilde yansıtmaktadır ve okullarda uygulanacak şekilde geliştirilmiştir (Elias, 2004; Merrell \& Gueldner, 2010).

Empati, problem çözme, sebat etme yeteneği ve kişinin duygularını yönetme yeteneği, öğrencilerin öğrenmesi için kritik becerilerdir. Öğrenciler bu becerileri, öğretmen, ebeveyn veya sınıf arkadaşı gibi uygun bir modeli gözlemleyerek öğrenebilirler. Öğrenmenin gerçekleşmesi için öğrencilerin tekrarlı uygulama yapması, özel düzeltici geribildirimler alması ve bu becerilerin düzenli olarak tekrar gözden geçirilmesi gerekir. Ancak, öğrencinin yetkin hale gelmesi için beceriyi uygulatırken çeşitli öğrenme deneyimleri sağlanmalıdır. Ek olarak, öğretmenler bu becerileri uygulatırken, hedeflenen olumlu geri bildirimlerle duygusal anlamda güvenli bir sınıf ortamı oluşturarak, öğrencinin daha başarılı bir şekilde öğrenme ve gerçekleştirme yeteneğini geliştirebilir (Ciotto \& Gagnon, 2018). Bu bağlamda, 3-12. sınıf aralığında öğrenim gören öğrencilere, hedeflenen sosyal ve duygusal yetenekleri kazandırmak için öğrenme ortamında kullanılabilecek en uygun modellerden birisi SDÖ modelidir.

SDÖ, duyguları tanıma ve yönetme, başkalarına karşı kaygı ve endişe oluşturma, sorumlu kararlar alma, etik davranma, olumlu bir ilişki kurma ve zorlayıcı durumları etkili bir şekilde çözme becerilerini geliştirme sürecidir. SDÖ, okullara sorunların önlenmesi ve öğrencilerin refah ve başarılarının arttırılması için bir çerçeve oluşturmakta ve aktif öğrenme yaklaşımını vurgulamaktadır (Collaborative for Academic, Social, \& Emotional Learning [CASEL], 2012; Zins, Weissberg, Wang, \& Walberg, 2004). Bu açılardan okullarda uygulanan SDÖ programları, öğrencilerin ilişki kurma, karar alma, zorluklara çözümler üretme gibi yaşamsal becerilerinin gelişmesini hedeflemektedir. Ayrıca hedeflenen okul çıktıları şunlardır: Olumlu sosyal davranış, daha az davranış problemleri, olumlu duygusal sağlık ve akademik başarı (CASEL, 2017).

Eğitmenlerin fiziksel ortamda SDÖ becerilerini öğretmeleri ve geliştirmeleri için, "sosyal ve duygusal öğrenmenin beş temel yeterlilikleri" olarak adlandırılan beş belirleyici beceri tanımlanmıştır (CASEL, 2012). Bu beceriler; karar alma sorumluluğu, ilişki becerileri, öz yönetim, sosyal farkındalık ve öz farkındalıktır (CASEL, 2012; Zins ve diğerleri, 2004):

Karar alma sorumluluğu: Kişinin davranışları ve başkalarıyla etkileşimleri hakkında güvenli, saygılı ve ahlaki kararlar verme becerisini ifade eder. Toplumsal problemleri çözmeyi ve ahlaki akıl yürütmeyi vurgulamaktadır. Kişi, sorumlu bir şekilde yalnızca kendinin değil, başkalarının da sosyal problemlerini önleyen ve çözen kararlar almaktadır.

İlişki becerileri: Sağlıklı dostluklar kurma ve sürdürme, başkalarını dinleme, birlikte çalışma yapma, çatışmaları yapıcı bir şekilde çözme ve başkalarına yardımcı olma becerisini ifade eder. 
Öz yönetim: Kişinin düşüncelerini, duygularını, dürtülerini ve davranışlarını farklı durumlarda etkili biçimde denetleyen ve düzenleyen becerileri ifade eder. Ayrıca, stres yönetimi, kendini motive etme, kişisel ve akademik hedeflere ulaşmaya yönelik çalışma ve düzenleme yapma da dahildir.

Sosyal farkındalık: Bireylerin başkalarının davranışlarını, duygularını, farklılıklarını ve bakış açılarını anlamalarına ve empati göstermelerine olanak tanımaktadır. Ayrıca, davranışlar için sosyal ve ahlaki normları anlama becerisi, farklı geçmişlerden ve kültürlerden gelen insanlarla empati kurabilme becerisini de ifade eder.

Öz farkındalık: Kişinin kendi duygu ve düşüncelerini belirleme, düşüncelerin ve duyguların kişinin davranışını nasıl etkilediğini anlamaya yönelik becerileri ifade eder. $\mathrm{Bu}$, bir kişinin güçlü ve sınırlı olduğu konuların değerlendirilmesini ve haklı bir güven ve iyimserlik duygusuna sahip olmasını içerir.

Öğrencilerin sosyal-duygusal yeterlikleri ile okula katılımları arasında olumlu bir ilişki olduğu düşünülmektedir. Yapılan çalışmalar, öğrencilerin okula daha fazla katılım göstermesi (Kwon, Kim, \& Sheridan, 2012) ve daha fazla akademik başarı göstermesi için daha fazla sosyal-duygusal yeterliliğe sahip olması gerektiğini göstermiştir (Malecki \& Elliot, 2002). Sosyal-duygusal yeterlik ile ceza verme/uzaklaştırma arasındaki ilişkiye bakıldığında, daha güçlü sosyal-duygusal yeterliğe sahip öğrencilerin daha az davranış sorunu gösterdiği yapılan çalışmalar tarafından desteklenmektedir (Bornstein, Hahn, \& Haynes, 2010).

Okullarda öğretmenlerin öğrencilerin sosyal davranışlarını, empati ve sorumluluklarını sergilediği tüm olayları gözlemlemesi mümkün değildir. Bu nedenle öğretmenler, öğrencilerin yeterliklerinin gereğinden az veya fazla olduğunu rapor edebilmektedirler. Örneğin araştırmalar; öğretmenlerin, öğrencilerin daha az zorbalığa maruz kaldığını ve zorbalığa karışan öğrencilere kıyasla bu durumu daha az raporladığını göstermiştir (Bradshaw, Sawyer, \& Brennan, 2007).

Mantz, Bear, Yang ve Harris'in (2016) ölçek geliştirme çalışmasında, daha fazla sosyal farkındalık, başkalarıyla ilişki kurma, kendini yönetme ve karar alma sorumluluğu gösterme becerilerine sahip öğrencilerin okullarında daha fazla zaman geçirdiklerini ortaya çıkarmışlardır. Ayrıca öğrencilerin sosyal farkındalık, başkalarıyla ilişki kurma, kendini yönetme ve karar alma sorumluluğu gösterme becerilerine daha fazla sahip olduklarını rapor eden okullarda, öğrencilerin okuldan kovulmauzaklaştırma oranının daha düşük olduğu tespit edilmiştir. Bu bulgulara paralel olarak, sosyal-duygusal yeterlikleri yüksek olan öğrenciler ile akademik başarıları arasında pozitif bir ilişki olduğunu (Malecki \& Elliot, 2002) ve sosyal-duygusal yeterliğe sahip öğrencilerin daha az davranış sorunları olduğunu (Bornstein ve diğerleri, 2010) gösteren çalışmalar mevcuttur.

SDÖ programları ile öğrencilerin sosyal-duygusal yeterliklerini geliştirmeye yönelik uygulamalar yapılmaktadır. Bu uygulamaların geribildirimlerini alabilmek için sosyal-duygusal yeterlikleri değerlendiren, psikometrik olarak ölçebilen ve okullara yüksek pratik faydalar sağlayan araçlara ihtiyaç duyulmaktadır. Mantz ve diğerlerinin (2016) SDÖ programlarını kapsayan ölçeklerle ilgili yaptıkları araştırmalarda, geliştirilen ölçeklerin uzun olması, gözlem-kodlama yöntemi ile gözleyici ve kodlayıcı güvenirliğinin düşük olması, değerlendirmesi uzun zaman alan kontrol listelerinin olması, doğrudan değerlendirmenin yapılması gibi çok da pratik yararları olmayan 
ölçme araçlarını olduğunu tespit etmişlerdir. Türkiye'de Sosyal Duygusal Öğrenme Becerileri Ölçeği (Kabakçı \& Owen, 2010) ve Sosyal-Duygusal Öğrenme Ölçeği (Aygun \& Taskin, 2017) gibi ölçek geliştirme ve daha çok Coryn, Spybrook, Evergreen ve Blinkiewicz (2009) tarafından geliştirilen Sosyal Duygusal Öğrenme Ölçeği’nin farklı yaş gruplarında geçerlik-güvenirliğinin yapıldığı çalışmalara rastlanılmıştır. Mevcut ölçeklerin madde sayılarının fazla olduğu ve belirli yaş gruplarına uygulandığ belirlenmiştir. Bu çalışmada uyarlanan DSDY-Ö’nün ise 12 maddeden oluştuğu ve 312. sınıf aralığındaki öğrenci gruplarının tümüne rahatlıkla uygulanabildiğ araştırmacılar tarafından ifade edilmektedir. Ayrıca, SDÖ’nün ülkemizde de özellikle özel eğitim kurumlarında sıkça kullanıldığı gözlenmektedir. $\mathrm{Bu}$ bağlamda, eğitim ortamlarında SDÖ kapsamında geliştirilmesi hedeflenen sosyal ve duygusal becerilerin değerlendirilmesi için; kısa olması ve tüm yaş gruplarını kapsaması açısından okullarda daha pratik faydalar sağlayacağı düşünülen DSDY-Ö’nün Türk diline uyarlanması uygun görülmüştür.

SDÖ’nün sosyal-duygusal yeterlik seviyelerine uygun maddeleri içeren, madde sayısı az, öğretim süresi kısa, 3-12. sınıf aralığındaki öğrenci gruplarının tümüne uygulanabilen ve öğrencilerin kendilerinin cevaplayabileceği bir ölçme aracına ihtiyaç duyulmaktadır. Bu bağlamda araştırmanın amacı, diğer ölçme araçlarına göre okullara daha pratik faydalar sağlayacağı düşünülen Delaware Sosyal-Duygusal Yeterlik Ölçeği (DSDY-Ö)'nün Türk diline kazandırılmasıdır. DSDY-Ö ile öğrencilerin okula devamı, iletişim becerisi, karar alma ve akademik başarısı hakkında ipuçları toplanabilir ve elde edilen verilere göre eksik sosyal-duygusal yeterliklerini geliştirmeye yönelik SDÖ programları uygulanabilir.

\section{Yöntem}

Çalışma kapsamında, ölçeğin dil eşdeğerliğinin sağlanması ve faktör yapısının sınanması hedeflenmiştir.

\section{Çalışma Grubu}

Araştırmanın AFA için çalışma grubunu, amaçlı uygun örnekleme yöntemine göre seçilen, 2017-2018 eğitim-öğretim yılının güz döneminde, Milli Eğitim Bakanlığına bağlı farklı okul türlerinde öğrenim gören toplam 338 lise öğrencisi oluşturmaktadır. Öğrencilerin 154'ü (\%45.6) kı, 184'ü (\%54.4) erkektir. Yaşlarına göre 83’ü (\%24.6) 15 yaşında, 90’ı (\%26.6) 16 yaşında, 78’i (\%23.1) 17 yaşında ve 87'si (\%25.7) 18 yaşındadır.

Araştırmanın DFA için çalışma grubunu, amaçlı uygun örnekleme yöntemine göre seçilen, Milli Eğitim Bakanlığına bağlı farklı okul türlerinde öğrenim gören farklı 220 lise öğrencisi oluşturmaktadır. Öğrencilerin 104'ü (\%47.3) k1z, 116’s1 (\%52.7) erkektir. Yaşlarına göre 49'u (\%24.5) 15 yaşında, 48'i (\%24.0) 16 yaşında, 50’si (\%25.0) 17 yaşında ve 53’ü (\%26.5) 18 yaşındadır.

\section{Veri Toplama Aracı}

Delaware Sosyal-Duygusal Yeterlik Ölçeği (DSDY-Ö). Mantz ve diğerleri (2016), psikometrik olarak öğrencilerin sosyal-duygusal yeterliklerini değerlendirmek amacıyla bir ölçek geliştirmişlerdir. Ölçeğin orijinal adı "The Delaware SocialEmotional Competency Scale (DSECS-S)"dir ve özgün dili İngilizcedir. DSDY-Ö, 
Delaware Okul Ölçekleri-Öğrenci Sürümleri [The Delaware School Surveys-Student Version (DSS-S)]'nin bir parçasıdır ve bağımsız olarak kullanılabilir. Delaware Okul Ölçekleri-Öğrenci Sürümleri; ilkokul, ortaokul ve lisede öğrenim gören 3-12. sinıf öğrencileri için tasarlanmıştır. Ölçekler, öğrencilerin okul iklimini algılamalarını, okula katılım durumlarını ve zorbalık mağduriyetine maruz kalma sıklıklarını değerlendirmektedir (Bear ve diğerleri, 2016).

Ölçeğin orijinali 12 maddeden oluşmaktadır. Öğrencilerin sosyal-duygusal yeterliklerini değerlendirmek için maddeler dört alt boyuta ayrılmıştır ve her alt boyutta üç madde yer almaktadır: Karar alma sorumluluğu (1, 5 ve 9. maddeler), ilişki becerileri (4, 8 ve 12. maddeler), öz yönetim (3, 7 ve 11. maddeler), sosyal farkındalık (2, 6 ve 10. maddeler). Ölçekte yer alan maddeler 4'lü Likert skalasında puanlanmaktadır. Ölçekte birinci madde ters puanlanmaktadır. Ölçekten alınabilecek en düşük puan 12, en yüksek puan 48'dir. Örnek madde olarak "Yaptığım hatadan ders çıkarmada iyiyimdir (karar alma sorumluluğu)", "Başkalarının nasıl hissettiğini önemserim (sosyal farkındalık)", "Davranışa geçmeden önce düşünürüm (öz yönetim)", "Başkalarıyla iyi geçinirim (ilişki becerileri)" şeklinde verilebilir.

Ölçek, Delaware'de 126 ilkokul, ortaokul ve lise kamu okullarının 3-12. sınıflarında öğrenim gören toplam 32.414 öğrenciye uygulanmıştır. İki alt örnek üzerinde yapılan doğrulayıcı faktör analizi (DFA), önerilen ikinci dereceden modelin uyum indeksi için $\chi 2=1357.93$ (50, N=16.205), $p$ <.001; CFI=.957, RMSEA=.040 [.038, .042] ve $\mathrm{SRMR}=.030$ değerlerini vermiştir. Örneklemin yaklaşık yarısında ikinci rastgele bölünmüş uyum indeksi için ise $\chi 2=1380.51(50, N=16.205), \quad p<.001$; $\mathrm{CFI}=.959$, RMSEA=.041 [.039, .043] ve SRMR=.029 değerlerini vermiştir. Ölçeğin toplam sosyal-duygusal yeterlik puanları ve alt boyutları arasındaki korelasyon katsayılarına bakıldığında; alt boyutlarda .65 ile .95 arasında orta ve yüksek korelasyon, toplamda ise .47 ile .82 arasında korelasyon hesaplanmıştır $(p<.001)$. İç tutarlılık katsayıları ise .58 ile .69 arasında, toplamda ise .84 olduğu belirlenmiştir (Mantz ve diğerleri, 2016).

\section{İşlem}

Ölçek uyarlama sürecinden önce gerekli izin DSDY-Ö’yü geliştiren araştırmacılardan biri olan George Bear'dan e-posta aracılığ 1 ile alınmıştır. Sonrasında uyarlama ile ilgili uygulamanın yapılabilmesi için Bursa İl Milli Eğitim Müdürlüğü’nden resmi izin alınmıştır. Uygulama öncesi öğrencilere çalışma ile ilgili bilgi verilmiştir. Ölçek gönüllü olan öğrencilere uygulanmış, öğrencilerin yaklaşık 15 dakika içinde ifadeleri cevapladığı gözlenmiştir.

\section{Çeviri ve Dil Eşdeğerlik Çalışması}

Öncelikle üç bağımsız çevirmen tarafından ölçeğin Türkçeye çevirisi yapılmış, sonrasında Türkçe form Geri-Çeviri Yöntemiyle (Back-Translation Methods) tekrar İngilizceye çevrilmiştir. Son olarak iki dil eğitimi alan uzmanının değerlendirmesi sonucunda Türkçe form elde edilmiştir. Ölçeğin orijinal hali ve Türkçe hali arasındaki tutarlılığı sağlamak amacıyla dilsel eşdeğerlik çalışması yapılmıştır (Hambleton \& Bollwark, 1991). Dilsel eşdeğerlik çalışması için lise son sınıfta öğrenim görmekte olan 140 öğrenciden İngilizce dersi sınav not ortalaması en yüksek olan 35 öğrenciye, iki hafta arayla İngilizce ve Türkçe form uygulanarak aradaki puanların tutarlılığı test 
edilmiştir. Korelasyon katsayısını hesaplamak için ölçek puanlarının normallik dağılımına bakılmış, öğrencilerin ölçekten aldıkları puanların -1.5 ve +1.5 standart sapma aralığında olduğu tespit edilerek verilerin normal dağıldığ gözlenmiştir (Tabachnick \& Fidell, 2013). Öğrencilerin her iki uygulamadan aldıkları puanlar arasındaki tutarlılığı test etmek için Pearson Momentler Çarpım Korelasyon katsayısına bakılmış; İngilizce ve Türkçe ölçekler arasında yüksek düzeyde, pozitif ve anlamlı bir ilişki olduğu görülmüştür $[r(35)=.81, p<.05]$. Buna göre iki ölçek arasındaki yüksek korelasyon, çeviride dilsel eşdeğerliğin sağlandığını göstermektedir.

Ölçeğin dilsel eşdeğerliği sağlandıktan sonra; anlamsal olarak uygunluğunu değerlendirmek amaciyla Türkçe form, lise son sınıfta öğrenim gören 10 öğrenciye uygulanmıştır. Öğrencilerin yorumları doğrultusunda ölçek üzerindeki bazı ifadeler düzenlenmiş, Türk Dili ve Edebiyatı Öğretmeninden uzman görüşü alınarak ölçeğe son şekli verilmiştir.

\section{Verilerin Analizi}

DSDY-Ö’nün geçerlik çalışmasında kapsam geçerliği için uzman görüşüne, yap1 geçerliği için DFA ve AFA yöntemlerine başvurulmuştur. Güvenirlik çalışmasında iç tutarlılık katsayısı için Cronbach Alpha ve Korelasyon katsayısı hesaplanmıştır. Verilerin analizinde LİSREL 8.7 ve SPSS 23 İstatistik Programları kullanılmıştır.

\section{Bulgular}

\section{Ölçeğin Geçerlik Çalışmaları}

DSDY-Ö’ye ilişkin orijinal kültürdeki yapının doğrulanıp doğrulanmadığını belirlemek amaciyla madde ve alt boyutlarla uyumlu olarak 338 lise öğrencisi veri grubuyla DFA yapılmıştır. Analiz öncesi birinci madde ters puanlandığı için çevirme işlemi yapılmıştır. DFA sonucunda model veri uyumu şu şekildedir: $\chi 2(48)=174.24$, $p<.001, \chi 2 / s d=3.63, \mathrm{RMSEA}=.088, \quad \mathrm{SRMR}=.063, \mathrm{CFI}=.94, \mathrm{NFI}=.92, \mathrm{NNFI}=.92$, GFI=.92. Maddelerle boyutları arasındaki yol katsayılarına bakıldığında, karar alma sorumluluğu için .18-.53; ilişki becerileri için .07-.43; öz yönetim için .32-.50 ve sosyal farkındalık için .52-.69 arasında değiştiği gözlenmiştir. Sonrasında maddeler ve alt boyutlar arasındaki $\mathrm{t}$ değerlerine bakılmış ve bazı maddelerin .05 düzeyinde anlamlı olmadığı tespit edilmiştir. Dolayısıyla, ölçekten madde atımı yapılarak teorik yapıya uygun yeni bir model kurmak amacıyla AFA yapılmasına karar verilmiştir (Asparouhov \& Muthén, 2009; Byrne, 2010).

Açımlayıcı faktör analizi (AFA). AFA'da döndürme öncesi 12 madde için öz değeri 1.00' den büyük üç alt boyut oluştuğu gözlenmiştir. Oluşan alt boyutlar varyansın \%56.156'sını açıklamaktadır. Döndürme öncesi maddeler arası düzeltilmiş korelasyon değeri .30 un altında olan 1 ve 12. maddeler ölçekten çıkarılmış (Büyüköztürk, 2016) ve 10 madde ile işleme devam edilmiştir. Sonrasında temel bileşenler analizi kullanılarak Varimax dik eksen döndürmesi yapılmış ve madde öz değeri 1.00'den büyük iki alt boyut oluştuğu belirlenmiştir. Örneklem büyüklügünün geçerliğini test etmek için yapılan işlem sonrasında KMO değerinin .852, Bartlett's Sphericity testinin ve Ki-Kare değerinin anlamlı çıktığı gözlenerek $(p<.05)$ elde edilen verinin faktör analizi için uygun ve faktörleştirilebilir olduğu belirlenmiştir $\left[X^{2}=1029.64, d f=45, p<.001\right]$ (Büyüköztürk, 2016; Tabachnick \& Fidell, 2013). 
Analiz sonucunda elde edilen iki alt boyutun toplam öz değeri 5.415 ve açıkladığı varyans \%54.149'dur. Tavşancıl (2002), toplam varyans oranının \%40 ile \%60 arasında değer almasının ölçeğin faktör yapısının güçlülüğüne işaret ettiğini belirtmektedir. Tablo 1'de görüldüğü gibi, birinci alt boyutun öz değeri 4.088, açıkladığı varyans \%40.883, ikinci alt boyutun öz değeri 1.327 , açıkladığı varyans \%13.26 olarak bulunmuştur. Ölçeğin özgün halinde dört alt boyut bulunmasına rağmen; analiz sonucunda, maddelerin iki alt boyutta toplandığı ve farklı alt boyutlara dağıldı̆̆ gözlenmiştir. $\mathrm{Bu}$ nedenle iki alt boyutlu yapı literatüre uygun olarak yeniden isimlendirilerek birinci alt boyuta öz farkındalık, ikinci alt boyuta sosyal farkındalık isimleri verilmiştir. AFA sonucu elde edilen öz değer grafiği Şekil 1'de verilmiştir.

\section{Şekil 1. AFA Öz Değer Grafiği}

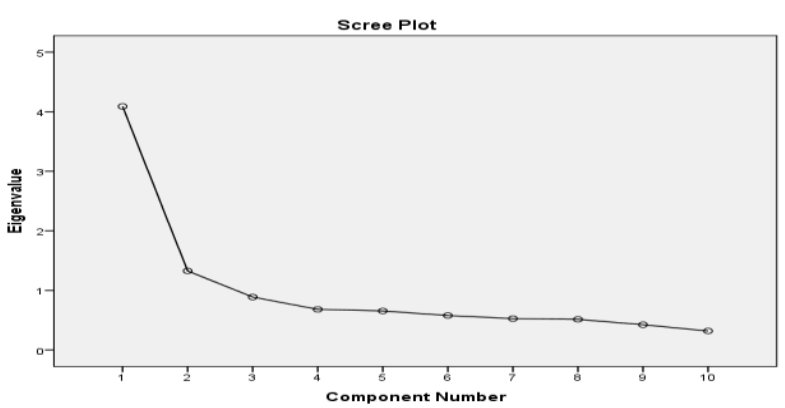

Şekil 1'deki öz değer grafiği incelendiğinde, ikinci maddeden sonraki maddelerin birbirlerine yakın değerlere sahip oldukları görülmüş ve ölçek iki alt boyutlu olarak ele alınmıştır. 
Tablo 1

AFA'dan Elde Edilen Madde Toplam Korelasyonlarl ve Döndürülmüş Faktör Yük Değerleri $(F Y)$

\begin{tabular}{ccccc}
\hline Madde No & Yeni Madde No & $\begin{array}{c}\text { Madde Toplam } \\
\text { Korelasyonu }\end{array}$ & Öz Farkındalık & Sosyal Farkındalık \\
\hline 3 & O1 & .60 & .75 & \\
4 & O2 & .39 & .72 & \\
5 & O3 & .57 & .61 & \\
7 & O4 & .51 & .71 & \\
9 & O5 & .67 & .71 & .66 \\
2 & S6 & .57 & & .76 \\
6 & S7 & .44 & & .71 \\
8 & S8 & .53 & & .77 \\
10 & S9 & .52 & & .51 \\
11 & S10 & .49 & 4.088 & 1.327 \\
\hline & Öz değer & & 40.883 & 13.266 \\
\hline
\end{tabular}

Tablo 1'e göre, ölçeğin madde toplam korelasyonlarının .39-.67 arasında değiştiği görülmektedir. Korelasyon katsayısı, .70-1.00 arasında yüksek; .70-.30 arasında orta ve .30-.00 arasında düşük düzeyde bir anlam ifade etmektedir (Büyüköztürk, 2016). Dolayısıyla, madde toplam korelasyon değerlerinin orta düzeyde olduğu görülmektedir. Ölçeğin faktör yük değerlerinin ise birinci alt boyutta .61-.75 arasında, ikinci alt boyutta ise .51-.76 arasında olduğu gözlenmektedir. Buna göre faktör yük değerlerinin orta ve yüksek düzeyde ilişkiye sahip olduğu ifade edilebilir (Büyüköztürk, 2016). 
Doğrulayıcı faktör analizi (DFA). DSDY-Ö'nün AFA'dan elde edilen iki alt boyutlu yapısının test edilmesi için farklı 220 öğrenci grubuyla DFA yapılmıştır. Modelin path diagramı Şekil 2'de verilmiştir.

Şekil 2. Modelin Path Diagramı

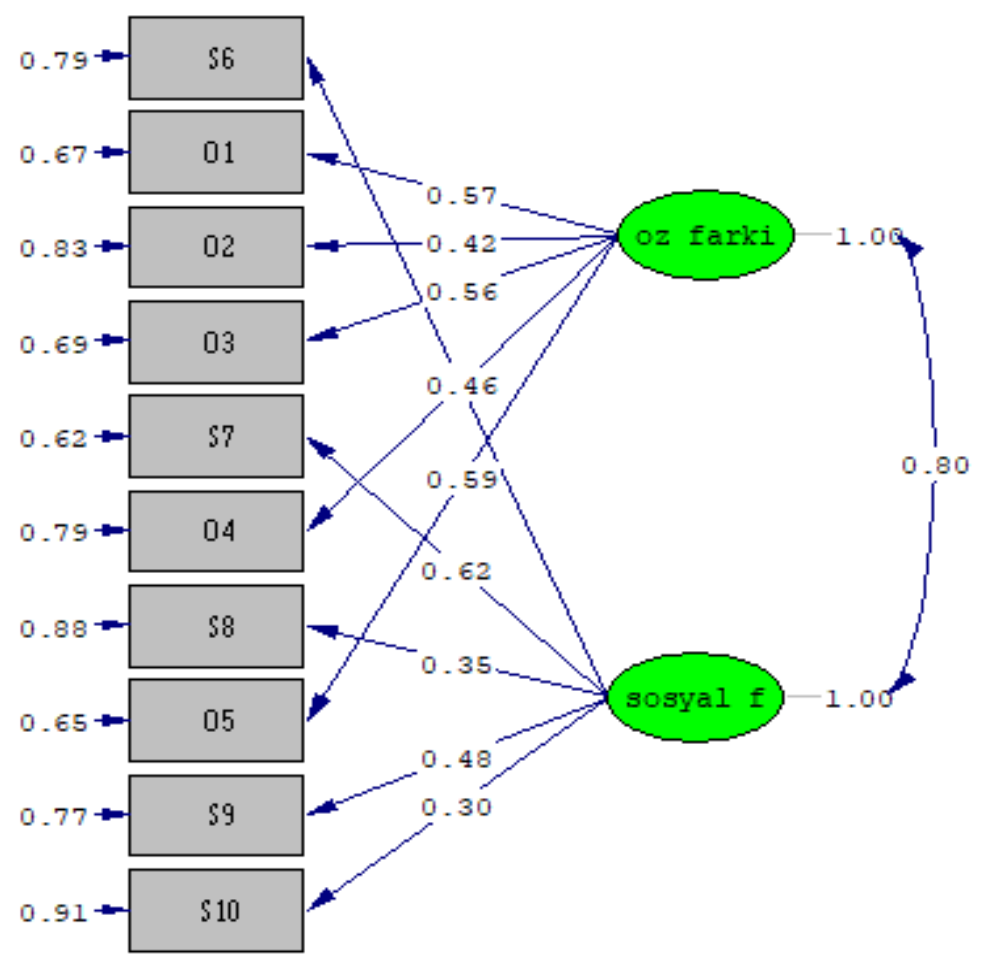

Şekil 2'de, DFA için faktör yük değerlerinin .30 ile .62 arasında, hata varyans değerlerinin .62 ile .91 arasında olduğu ve tamamının anlamlı bir düzeye ulaştığı görülmektedir. Maddeler ve boyutlar arasındaki yol katsayılarının öz farkındalık için .42-.59, sosyal farkındalık için .30-.62 arasında olduğu görülmektedir. Açıkladığ varyans ve ilişki değerleri orta ve üstü olduğu için bu değerler yeterli kabul edilir (Büyüköztürk, 2016). Modelin uyum iyiliği değerleri Tablo 2'de sunulmuştur.

Tablo 2

DFA Uyum İyilĭgi Dĕgerleri

\begin{tabular}{cccccccccc}
\hline$X^{2}$ & $s d$ & $x^{2} / s d$ & $P$ & GFI & CFI & NFI & NNFI & SRMR & RMSEA \\
\hline 52.52 & 34 & 1.54 & 0.0 & .95 & .95 & .89 & .94 & .038 & .050 \\
\hline
\end{tabular}

Tablo 2 incelendiğinde, Ki- kare değeri $\chi^{2}(34, N=338)=52.52, p<.001$ olarak saptanmıştır. Yapılan hesaplama sonucunda $\chi 2 / s d=1.54$ değerinin ve RMSEA=.050, $\mathrm{SRMR}=.038, \mathrm{CFI}=.95, \mathrm{NFI}=.89$, NNFI=.94, GFI=.95 değerlerinin kabul edilebilir ve mükemmel uyum değerlerinde olduğu görülmüsstür (Hu \& Bentler, 1999). Modelin RMSEA ve SRMR değerlerinin 0.08'den küçük olması (Hu \& Bentler, 1999) ve $\chi 2 / s d$ değerinin 5 'ten küçük olması (Sümer, 2000) modelle veri uyumunun güçlü olduğunu ve ölçeğin faktör yapısının kabul edilebilir olduğunu göstermektedir. İki alt boyutlu modele ilişkin $t$ testi değerleri Tablo 3 'te sunulmuştur. 
Tablo 3

DFA'dan Elde Edilen t-testi Dĕgerleri

\begin{tabular}{cccccc}
\hline Madde No & $t$ değeri & Madde No & $t$ değeri & Madde No & $t$ değeri \\
\hline O1 & $7.67^{*}$ & O5 & $8.00^{*}$ & S9 & $6.09^{*}$ \\
O2 & $5.42^{*}$ & S6 & $5.87^{*}$ & S10 & $3.77^{*}$ \\
O3 & $7.45^{*}$ & S7 & $7.94^{*}$ & & \\
O4 & $6.10^{*}$ & S8 & $4.40^{*}$ & & \\
\hline
\end{tabular}

$* p<.01$

Tablo 3 incelediğinde, AFA sonucu çıkarılan iki maddeden sonra tekrar yapılan DFA analizinde $t$ değerlerinin anlamlı bir değer aldığı görülmektedir. Kline (2011)'a göre, $t$ değeri için 1.96'dan büyük değerler .05 düzeyinde, 2.58'in üzerindeki değerler .01 düzeyinde anlamlıdır. Buna bağlamda, $t$ değerlerinin tamamının .01 düzeyinde anlamlı olduğu anlaşılmaktadır.

\section{Ölçeğin Güvenirlik Çalışmaları}

Cronbach Alpha güvenirlik katsayısı. DSDY-Ö’nün Türkçe formunun iç tutarlık katsayısının belirlenmesi için Cronbach Alpha ve Korelasyon Katsayısı hesaplanmış ve değerler Tablo 4'te verilmiştir.

Tablo 4

Alt Boyutların Ortalama (Ort), Standart Sapma (Ss), Korelasyon Katsayıları ve Cronbach Alpha Dĕgerleri

\begin{tabular}{lcc}
\hline Alt Boyutlar & Öz Farkındalık & Sosyal Farkındalık \\
\hline Öz Farkındalık & 1.00 & - \\
Sosyal Farkındalık & $.53^{*}$ & 1.00 \\
Ss & 3.94 & 3.61 \\
Ort & 13.99 & 13.90 \\
Cronbach Alfa & .79 & .76 \\
\hline
\end{tabular}

$* p<.01$

Analiz sonucunda ölçeğin iki alt boyutlu yapısına ilişkin Cronbach Alpha güvenirlik katsayısı .70 olarak bulunmuştur. Tablo 6'da görüldüğü gibi, alt boyutlara ilişkin Cronbach Alpha güvenirlik katsayısı birinci alt boyutta .79, ikinci alt boyutta .76 olarak tespit edilmiştir. Kalaycı (2010), Cronbach Alpha güvenirlik katsayısına bağlı olarak ölçeğin güvenirliğinin .60-.80 arası oldukça güvenilir, .80-1.00 arası yüksek derecede güvenilir olduğunu belirtmiştir. Dolayısıyla, ölçekteki ifadelerin geçerliklerinin yüksek olduğu ve ifadelerin aynı davranışı ölçmeye yönelik olduğu ifade edilebilir.

Ayrıca, öz farkındalık ve sosyal farkındalık maddelerine ilişkin korelasyon katsayısı değerinde pozitif yönlü anlamlı doğrusal bir ilişki olduğu gözlenmiştir 
$\left[r_{(338)}=.53 ; p<.01\right]$. Korelasyon -1 ile +1 arasında değerler alır (Alpar, 1998). Bu durum, öz farkındalığı yüksek olan öğrencinin sosyal farkındalığı da yüksektir ya da tersi şeklinde söylenebilir.

Test-Tekrar test güvenirliği. DSDY-Ö’nün Türkçe formunun ölçtüğü nitelik açısından kararlılığını test etmek için test-tekrar test yöntemi kullanılmıştır. Bunun için ölçek lise son sınıfta öğrenim gören 60 öğrenciye iki hafta ara ile uygulanmıştır. Öğrencilerin her iki uygulamadan aldıkları puanlar arasındaki kararlılığı test etmek için Pearson Momentler Çarpım Korelasyon Katsayısına bakılmış; her iki uygulama arasında yüksek düzeyde, pozitif ve anlamlı bir ilişki olduğu tespit edilmiştir $\left[r_{(60)}=.73\right.$, $p<.05]$.

\section{Sonuç ve Tartışma}

$\mathrm{Bu}$ çalışmada, öğrencilerin sosyal-duygusal yeterliklerini değerlendirmek amacıyla geliştirilen bir ölçeğin Türkçeye uyarlanmasına yönelik bulgular değerlendirilmiştir. Çalışmada, ölçeğin Türkçe formunun dil eşdeğerlik çalışmasının yapılması, geçerliğin araştırılması ve güvenirliği sınanması sağlanmıştır. Araştırmadan elde edilen sonuçlar, DSDY-Ö'nün öğrencilerin sosyal-duygusal yeterliklerini değerlendirmek için geçerli ve güvenilir bir araç olduğunu göstermektedir.

DSDY-Ö'nün yapı geçerliğinin test edilmesi amacıyla yapılan AFA sonucunda iki alt boyutlu yapı elde edilmiştir. Maddelerin orijinal ölçekteki alt boyutlara dağılımı göz önüne alınarak iki alt boyuta "öz farkındalık ve sosyal farkındalık" isimleri verilmiştir. Analiz sonucunda, sosyal farkındalık alt boyutunda 2, 6 ve 10. maddelerin orijinal ölçekteki gibi yerleştiği, ilişki becerileri alt boyutunda yer alan 8 . maddenin ve öz yönetim alt boyutunda yer alan 11. maddenin ilave olduğu; öz farkındalık alt boyutunda ise orijinal ölçekteki öz yönetim alt boyutunda yer alan 3, 7, 11. maddeler ve karar alma sorumluluğu alt boyutunda yer alan 5 ve 9. maddenin yer aldığ1 tespit edilmiştir. Dolayısıyla sosyal farkındalık ve ilişki becerilerini temsil eden maddelerin sosyal farkındalık alt boyutunda toplandığı, öz yönetim ve karar alma sorumluluğunu temsil eden maddelerin öz farkındalık alt boyutunda toplandığı gözlenerek; orijinal DSECS-S ile Türkçe DSDY-Ö’nün benzerlik gösterdiği ifade edilebilir. Ölçek alt boyutlarındaki farklılık, Amerika Birleşik Devletleri ile Türk eğitim sistemi arasındaki farklılıklardan kaynaklandığı şeklinde açıklanabilir (Erdoğan, 2003). Ayrıca, AFA sonucunda açıklanan toplam varyans oranının \% 54.149 olarak bulunmas1; dolayısıyla açıklanan varyans oranının \% 40 ile \% 60 arasında değer alması ölçeğin faktör yapısının güçlü olduğunu göstermektedir (Tavşanc1l, 2002).

AFA'dan elde edilen iki boyutlu yapının test edilmesi için farklı veri grubuyla DFA yapılmıştır. DFA'dan elde edilen sonuçlarda, $\chi 2 / s d=1.54$ değerinin mükemmel düzeyde bir değere sahip olduğu, RMSEA=.050, SRMR=.038, CFI=.95, NFI=.89, $\mathrm{NNFI=.94,} \mathrm{GFI=.95} \mathrm{uyum} \mathrm{iyiliği} \mathrm{değerlerinin} \mathrm{kabul} \mathrm{edilebilir} \mathrm{ve} \mathrm{mükemmel} \mathrm{uyum}$ düzeyinde olduğu saptanmıştır (Brown, 2006). Bu bağlamda, kurulan modelin verilerle yeterli düzeyde uyum gösterdiği ve maddelerin sosyal-duygusal yeterlik davranışlarını ölçebildiği ifade edilebilir.

DSDY-Ö’nün Türkçe formunun iki alt boyutlu yapısına ilişkin Cronbach Alpha güvenirlik katsayısı .70, bulunmuştur. Güvenirlik katsayısının .70 ve üstü olması durumunda ölçme aracının yüksek derecede güvenilir olduğu kabul edilir (Büyüköztürk, 
2016). DSDY-Ö’nün Türkçe formunun ölçtüğü nitelik açısından zaman bağlamında kararlılığını istatistiksel olarak test etmek için hesaplanan test-tekrar test güvenirlik katsayıs1 .73 olarak hesaplanmıştır. Buna göre ölçeğin her iki uygulaması arasında yüksek düzeyde, pozitif ve anlamlı bir ilişki olduğu görülmüştür (Anastasi, 1982). Bu sonuca göre uygulamalar arasındaki kararlılığın yüksek düzeyde olduğu, dolayısıyla ölçeğin zaman içerisinde süratli değişiklik göstermeyen nitelikleri kararlı bir şekilde ölçebildiği kabul edilmiştir.

DSDY-Ö, sosyal-duygusal yeterliklerle uyumlu, ilkokuldan lise öğrencisine kadar kolaylıkla tamamlanabilen, ucuz, kısa zamanda doldurulan bir ölçek olarak geliştirilmiştir. Ölçek bu faydalarından dolayı, SDÖ programı geliştirme ve değerlendirme çalışmalarında eğitimcilere ve araştırmacılara pratik ve kullanışlı bir araç olarak hizmet etmektedir. Bu ölçeği okullarda kullanmak, eğitimcilerin öğrencilerin önemli sosyal-duygusal yeterlikleri gösterip göstermediklerini anlamaları açısından yardımcı olabilir. Öğrencilerin sosyal-duygusal yetkinlikleri olmadığını tespit eden okullar, SDÖ programı geliştirmeyi veya güçlendirmeyi hayata geçirebilirler. Daha düşük yeterlik düzeyi tespit edilen öğrencilerden belirli grupları (örneğin, belirli bir sınıftaki öğrencileri) incelemek için DSDY-Ö puanlarını kullanarak; küçük gruplarda SDÖ öğretimi yapma, SDÖ derslerinin frekansını artırma, güçlendirici SDÖ dersleri uygulama veya diğer sosyal-duygusal gelişim programlarına dâhil etme gibi öğrencilere ek destekler sağlanabilir.

Ölçeğin sınırlılıkları değerlendirildiğinde; bu ölçekte sadece öğrencilerin sosyalduygusal yeterlikleri hakkında bilgi verilebilir, okullarda öğrencilerin farklı sosyalduygusal alanlardaki güçlü ve zayıf yönleri tespit edilememektedir. Eğer bu yönde bir çalışma yapılacaksa ek araçlara ihtiyaç duyulabilir. Ayrıca DSDY-Ö, sosyal-duygusal yeterliklerin dördünü değerlendirir. Beşinci boyut olan öz farkındalık, ölçekte değerlendirilmeye alınmamıştır. Bunun sebepleri, benlik bilincinin değerlendirilmesinde istenen ebeveyn onamının daha üst düzeyde olması gerektiği; benlik saygısı ve benlik kavramını hedef alan programların hedeflenen sonuçların iyileştirilmesinde etkisiz olduğu; değişmesi çok muhtemel olmayan öğrenci yeterlikleri hakkında bilgi vermenin yapıcı görünmemesi; duyguları tanımlama becerilerinin okullarda nadiren dâhil edilmesi; benlik bilinci ile ilgili değerlendirmelerin küçük yaş grupları açısından avantajlı olmaması şeklinde özetlenebilir (Mantz ve diğerleri, 2016).

Ölçeğin uyarlanmasına yönelik sınırlılıklar değerlendirildiğinde; ölçek sadece lise öğrencilerine uygulanmıştır. İlkokul ve ortaokul öğrencilerini kapsayan bir çalışma için ölçeğin geçerlik ve güvenirlik analizleri yenilenmelidir. Ayrıca, ölçeğin uyarlanmasında analizden bazı maddelerin çıkarılması diğer uygulamalarda sonucun aynı olacağını göstermemektedir.

Sınırlılıklarına rağmen DSDY-Ö, madde sayısının kısa olması, sosyal-duygusal yeterliklerle uyumlu olması, öğretimi kolay olması, 3-12. sınıf yaş grubuna uygun olması gibi avantajlara sahiptir. Bu avantajlar göz önüne alındığında DSDY-Ö’nün, öğrencilerin sosyal-duygusal yeterliğini arttırmak isteyen eğitimciler ve araştırmacılar için pratik ve kullanışlı bir araç olarak hizmet edeceği düşünülmektedir. 


\section{Summary}

Purpose and Significance: Mantz, Bear, Yang, and Harris (2016) developed the DSECS$S$ to measure the social-emotional competence of the students psychometrically, and it is written in English. DSECS-S is part of the Delaware School Surveys-Student Version (DSS-S) and can be used independently. The DSS-S developed for primary school, secondary school and high school students from 3rd to 12 nd grade. The scales assess students' perceptions of the school climate, the classroom management techniques used by their teachers, their school engagement, and the frequency of bullying victimization (Bear et al., 2016). The aim of this study is to adapt The Delaware Social-Emotional Competency Scale into Turkish so that social-emotional competency of students can be examined through testing the language validity and conducting CFA and EFA.

Mantz et al. (2016) have been investigated scales related to the social-emotional competency. Many of the scales they have found have too many items or long timeconsuming checklists and also the reliability of other types of qualitative is discussable. There is a need for a scale which provides practical benefit, which is short and its cost is low. Given the disadvantages of the existing instruments, a short, inexpensive (free-touse) student self-report tool is needed to assess the social-emotional competencies. In this context, according to other instruments it is deemed appropriate to adapt the Delaware Social-Emotional Competency Scale (DSECS-S), which is thought to provide school with more practical use, into the Turkish language. It has been found out that no adaptation has been executed in Turkey regarding DSECS-S. In this context, it is important that Turkish literature obtain a diagnostic instrument to determine selfreported social-emotional competence of students. Apart from measuring socialemotional competence, DSECS-S can be used to collect clues about students' school attendance, academic achievement, communication skills, decision making, and then apply such programs to develop incomplete social-emotional competences.

Method: The language validity has been tested and CFA and EFA have been administrated. Thirty five students responded the English and Turkish versions of the scale separately within a two weeks interval so that the language validity of the scale tested. The Pearson Moments Multiplication Correlation coefficient was calculated to test the consistency between students' scores on both versions. In addition, while the sample for EFA consisted of 338 students, the sample for CFA consisted of 220 different students. The study groups of the study were selected by purposive sampling method. What's more, the test-retest method was administered to 60 students in order to test the stability of the Turkish version of the scale

Results and Discussion: According to The Pearson Moments Multiplication Correlation coefficient, it was found that there was a high positive correlation between English and Turkish versions $\left[r_{(35)}=.81, p<.05\right]$. This indicates that Turkish version of the scale has language validity. In order to test construct validity of the scale, firstly CFA was conducted and some items were not found to be meaningful due to the red arrow at the $t$ value of the model. It was decided to carry out EFA. Before the EFA, items 1 and 12, which were below the item total correlation of .30, were excluded from the scale and EFA was performed with the remaining 10 items. The first item excluded was in the 
sub-dimension of responsibility for decision-making, and the 12th item is in the subdimension of relationship skills. Two sub-dimensional structures have emerged as a result of the EFA on basic components and the Varimax rotation technique. As a result of the analysis, the total score of the two sub-dimensions obtained is 5.415 and the variance explained is $54.149 \%$. Considering the distribution of the items to the subdimensions of the original measure, the two sub-dimensions were determined which named as "self-awareness and social awareness".

It was determined that fit values of RMSEA $=.050, \mathrm{SRMR}=.038, \mathrm{CFI}=.95, \mathrm{NFI}=.96$, $\mathrm{NNFI}=.94$, GFI=.95, which are frequently used in CFA measurements, had good and excellent fit values (Hu \& Bentler, 1999). Findings acquired from the confirmatory factor analysis signify that factor structure of the scale shows an acceptable compatibility with the collected data. In order to calculate the reliability of the scale, Cronbach's Alpha internal consistency coefficient was used, Cronbach's Alpha reliability coefficient for the overall of the scale was found to be .70, and Cronbach's Alpha values for the sub dimensions were found between .79 and .76. The correlation coefficient between .80-1.00 is stated as highly perfect, between .60-.80 is perfect (Kline, 2011). High and statistically significant correlation coefficients indicate that the two sub-factors are responsibility components. Through the test-retest method, the Pearson Moments Multiplication Correlation Coefficient was tested to test the stability of the students' scores between the two applications; it was found that there was a high positive correlation between both methods $[r(60)=.73, p<.05]$.

Conclusions: It can be said that the established model has a satisfactory level of compliance, the whole scale has structural validity, and the scales can measure the socio-emotional competence of students. That is to say, factor structure of Turkish version of the scale is acceptable. All in all, all the findings show that the Turkish version of the scale of social-emotional competence can be applied to high school students in schools. The scale is a valid and reliable for determining the socialemotional competencies. 


\section{Kaynakça}

Alpar, R. (1998). Istatistik ve spor bilimleri. Ankara: Bağırgan.

Anastasi, A. (1982). Psychological testing. New York: Mac Millan Publishing Co. Inc.

Asparouhov, T., \& Muthén, B. (2009). Exploratory structural equation modeling. Structural Equation Modeling: A Multidisciplinary Journal, 16(3), 397-438.

Aygun, H. E., \& Taskin, C. S. (2017). Identifying psychometric properties of the socialemotional learning skills scale. Educational Policy Analysis and Strategic Research, 12(2), 43-61.

Bear, G., Yang, C., Harris, A.,Mantz, L., Hearn, S., \& Boyer, D. (2016). Technical manual for 2016 Delaware school survey: Scales of school climate; bullying victimization; student engagement; positive, punitive, and social emotional learning techniques; and the Delaware social and emotional competencies scale. Newark, DE: Center for Disabilities Studies.

Bornstein, M. H., Hahn, C.-S., \& Haynes, O. M. (2010). Social competence, externalizing, and internalizing behavioral adjustment from early childhood through early adolescence: Developmental cascades. Development and Psychopathology, 22, 717-735. https://doi.org/10.1017/ S0954579410000416.

Bradshaw, C. P., Sawyer, A. L., \& O'Brennan, L. M. (2007). Bullying and peer victimization at school: Perceptual differences between students and school staff. School Psychology Review, 36(3), 361-382.

Brown, T. A. (2006). Confirmatory factor analysis for applied research. New York: Guilford Press.

Büyüköztürk, Ş. (2016). Veri analizi el kitabı. Ankara: Pegem Akademi.

Byrne, B. M. (2010). Structural equation modeling with AMOS: Basic concepts, applications and programming. New York, NY: Taylor and Francis Group.

Ciotto, C.M., \& Gagnon, A.G. (2018) Promoting social and emotional learning in physical education. Journal of Physical Education, Recreation \& Dance, 89(4), $27-$ 33. https://doi.org/10.1080/07303084.2018.1430625

Collaborative for Academic, Social, and Emotional Learning. (2012). 2013 CASEL guide: Effective social and emotional learning programs. Preschool and elementary school edition. Chicago, IL: CASEL

Collaborative for Academic, Social, and Emotional Learning. (2017). SEL FAQ. Retrieved from http://www.casel.org/faqs/

Coryn, C. L. S., Spybrook, J. K., Evergreen, S. D. H., \& Blinkiewicz, M. V. (2009). Development and evaluation of the social-emotional learning scale. Journal of Psychoeducational Assessment, 27(3), 283-295.

Dusenbury, L., Weissberg, R. P., Goren, P., \& Domitrovich, C. (2014). State standards to advance social and emotional learning: Findings from CASEL's state scan of social and emotional learning standards, preschool through high school. Chicago: Collaborative for Academic, Social, and Emotional Learning.

Elias, M. (2004). The Connection between social-emotional learning and learning disabilities: Implications for intervention. Learning Disability Quarterly, 27, 53-63.

Erdoğan, İ. (2003). Çăğdaş ĕgitim sistemleri (5. bs.). İstanbul: Sistem Yayıncılık. 
Hambleton, R. K., \& Bollwark, J. (1991). Adapting tests for use in different cultures: Technical issues and methods. Bulletin of the International Testing Commission, 18, 3-32.

Hu, L. T., \& Bentler, P. M. (1999). Cutoff criteria for fit indexes in covariance structure analysis: Conventional criteria versus new alternatives. Structural Equation Modeling, 6(1), 1-55.

Jones, S. M., \& Bouffard, S. M. (2012). Social and emotional learning in schools: From programs to strategies (Social Policy Rep. No. 26. 4.). Society for Research in Child Development.

Kabakçı, Ö. F., \& Owen, K. F. (2010). Sosyal duygusal öğrenme becerileri ölçeği geliştirme çalışması. Ĕgitim ve Bilim, 35(157), 152-166.

Kalayc1, Ş. (2010). Faktör analizi, SPSS uygulamall çok değişkenli istatistik teknikleri (5. bs.). Ankara: Asil Yayın.

Kline, R. B. (2011). Principles and practice of structural equation modeling ( ${ }^{\text {nd }}$ ed.). New York London: The Guilford.

Kwon, K., Kim, E. M., \& Sheridan, S. M. (2012). A contextual approach to social skills assessment in the peer group: Who is the best judge? School Psychology Quarterly, 27, 121-133. https://doi.org/10.1037/a0028696

Malecki, C. K., \& Elliot, S. N. (2002). Children's social behaviors as predictors of academic achievement: A longitudinal analysis. School Psychology Quarterly, 17, 1-23. https://doi.org/10.1521/ scpq.17.1.1.19902

Mantz, L. S., Bear, G. G., Yang, C., \& Harris, A. (2016). Delaware social-emotional competency scale (DSECS-S): Evidence of validity and reliability. Child Ind Res. October 2016. https://doi.org/10.1007/s12187-016-9427-6.

Merrell, K. W., \& Gueldner, B. A. (2010). Social and emotional learning in the classroom. New York: Guildford Press.

Sümer N. (2000). Yapısal eşitlik modelleri: Temel kavramlar ve örnek uygulamalar. Türk Psikoloji Yazıları, 3(6), 49-74.

Tabachnick, B., \& Fidell, L. (2013): Using multivariate statistics $\left(6^{\text {th }}\right.$ international ed. cover edn). Thousand Oaks, NJ: Sage Publications.

Tavşanc1l, E. (2002). Tutumların ölçülmesi ve SPSS ile veri analizi. Ankara: Nobel Akademi.

Tezbaşaran, A. (1997). Likert tipi ölçek hazırlama kılavuzu. Ankara: Türk Psikologlar Derneği.

Zins, J. E., Weissberg, R., Wang, M. C., \& Walberg, H. J. (2004). Building academic success on social and emotional learning: What does the research say? New York: Columbia University Teachers College Press. 